\title{
Doença da arranhadura do gato por Bartonella quintana em lactente: uma apresentação incomum
}

\author{
Cat-scratch disease caused by Bartonella quintana in an \\ infant: an unusual presentation

\begin{abstract}
Zina Maria Almeida de Azevedo, Laurinda Yoko S. Higa, Paulo Roberto Boechat, Marcia Bastos Boechat e Fernando Klaplauch
\end{abstract}

Resumo Relato de caso de doença da arranhadura do gato (DAG), em um paciente lactente, com história epidemiológica negativa, descrevendo o rastreamento diagnóstico, a imagem ao ultra-som, a evolução clínica e o prognóstico. B. quintana foi identificada em aspirado de secreção ganglionar pelo método de PCR. B. henselae, embora seja o agente causal habitualmente responsável pela DAG, não foi isolada. Os autores concluem que a pesquisa de B. quintana e B. henselae deve ser incluída na investigação de adenites, principalmente quando a evolução é subaguda, mesmo em lactentes e, ainda que a história epidemiológica seja negativa.

Palavras-chaves: Doença da arranhadura do gato. Lactente. Adenomegalia. B. quintana. B. henselae.

Abstract This case study reports a typical clinical course of cat-scratch disease (CSD) in an infant without epidemiological data and presenting bilateral submandibular lymphadenopathy. The authors describe clinical course, ultrasound images, diagnosis and prognosis. Polymerase chain reaction (PCR) detected and identified $\mathrm{B}$. quintana in lymph node samples. B. henselae currently thought to be the causative agent of CSD was not detected. The PCR assays for $\mathrm{B}$. quintana and $\mathrm{B}$. henselae should be available for the investigation of lymphadenopathy, even if the infant has not had either cat or dog contact.

Key-words: Cat-scratch disease. Infant. Lymphadenopathy. B. quintana. B. henselae.

Desde a descrição da doença da arranhadura do gato como entidade clínica por Debré et al em 1950, o agente etiológico desta doença tem sido muito discutido. Nos últimos dois anos, trabalhos têm demonstrado o papel do gênero Bartonella (B.), em especial $B$. henselae, na etiologia desta doença, concluindo que a Afipia felis não tem um papel tão significativo como lhe era atribuído até então ${ }^{6}{ }^{19}$. A Bartonella quintana está mais freqüentemente associado à febre das trincheiras, angiomatose bacilar cutânea, endocardite, febre e bacteremia em imunossuprimidos e imunocompetentes, do que à DAG2891119.

Nós descrevemos aqui um caso de adenomegalia submandibular, cujo agente etiológico isolado pelo método de reação de cadeia de polimerase (PCR) foi $B$. quintana.

Departamento de Pediatria, Serviço de Pneumologia do Departamento de Pediatria, Departamento de Cirurgia Infantil e Serviço de Radiologia do Instituto Fernandes Figueira/FIOCRUZ; Urgências Pediátricas (URPE)/Policlínica de Botafogo.

Endereço para correspondência: Dra. Zina Maria Almeida de Azevedo. Depto de Pediatria/Instituto Fernandes Figueira/FIOCRUZ. Av. Rui Barbosa 716, Flamengo, 22250-020 Rio de Janeiro, RJ, Brasil.

Tel: 5521 553-0052 R: 5411, 5521 508-8143 (res); Fax: 5521 553-8094.

e-mail-zina@netrasun.iff.fiocruz.br

Recebido para publicação em 2/7/99. 


\section{RELATO DO CASO}

Paciente FMF, sexo feminino, 10 meses de idade, previamente hígido, iniciou quadro de febre $\left(38^{\circ} \mathrm{C}\right)$ e aparecimento súbito de tumoração submandibular. Sinais inflamatórios presentes: calor e dor. Paciente apresentava-se ativa e alegre, sem sinais de toxemia. Foi iniciado amoxacilina + ácido clavulínico. O hemograma revelou: $3,86.10^{5}$ hemácias; $\mathrm{H}^{\text {to: }}: 28 \%$; $\mathrm{Hb}: 10,3 \mathrm{~g} \%$; Leucometria: $12.800 ; 0 / 4 / 0 / 0 / 3 / 20 / 60 / 4$; velocidade de hemossedimentação (VHS) de $60 \mathrm{~mm}$. Em 48h houve piora do quadro febril $\left(39,5^{\circ} \mathrm{C}\right.$ a $\left.40^{\circ} \mathrm{C}\right)$, com a pele adjacente à tumoração adquirindo coloração violácea, sugerindo evolução para celulite. Simultaneamente, observou-se tumoração contralateral de consistência endurecida. A paciente foi internada e medicada com ceftriaxone e clindamicina por via endovenosa por 7 dias. $\mathrm{O}$ hemograma, no 5 o dia de internação, revelou: $3,80.10^{5}, \mathrm{H}^{\text {too: }} 29 \%$; $\mathrm{Hb}: 10,4 \mathrm{~g} \%$; leucometria: 18.500; 0/14/0/0/2/30/52/2; VHS $=76 \mathrm{~mm}$. PPD não reator. Dosagem de amilase: $89 \mathrm{mg} / \mathrm{dl}$. Após $72 \mathrm{~h}$ de internação, a paciente apresentou melhora da curva febril, mantendo 2 picos febris diários $\left(38^{\circ} \mathrm{C}\right.$ a $\left.38,5^{\circ} \mathrm{C}\right)$ e a pele íntegra, sem sinais inflamatórios evidentes. A tumoração submandibular bilateral tinha consistência endurecida, porém menos dolorosa à palpação. A ultrassonografia revelou imagens hipoecóicas em regiões submandibulares bilateralmente, de limites precisos e contornos regulares, medindo a direita $1,9 \times 2,0 \times 1,1 \mathrm{~cm}$ e a esquerda $1,8 \times 1,1 \times 1,9 \mathrm{~cm}$. A paciente permanecia em bom estado geral, alternando períodos de irritabilidade e de bom humor. A investigação diagnóstica incluiu o isolamento viral que revelou: a) imunofluorescência positiva para coxsackie $B$ em células na urina; isolamento negativo para os vírus da caxumba, CMV, rubéola e herpes; b) material de saliva (swab e aspirado): imunofluorescência positiva para coxsackie $B$ em células de saliva; isolamento negativo para RSV, adenovírus, parainfluenza 1 , $2,3,4, \mathrm{CMV}$, caxumba, influenza A e B e echovírus; c) teste anti-HIV negativo (ELISA); d) sorologias (ELISA): vírus da rubéola: IgG e IgM negativos; CMV: IgM negativo, IgG positivo; herpes vírus:
IgG e IgM negativos; Epstein-Barr: VCA IgG negativo, EBNA IgG negativo; toxoplasmose: IgG e lgM negativos. As hemoculturas foram negativas para germes piogênicos e fungos. Foi realizado ECG e ecocardiograma que não revelaram anormalidades.

Após a alta hospitalar a paciente foi mantida em acompanhamento ambulatorial sem antibioticoterapia. A evolução no 8 dia após a alta (18 dias de doença) revelou bom estado geral, aceitação irregular da dieta com exceção do seio materno, mantendo febre que variava de $37,7^{\circ} \mathrm{C}$ a $37,8^{\circ} \mathrm{C}$, com picos de até $38^{\circ} \mathrm{C}$. A tumoração apresentava sinais de flutuação sendo indicado a drenagem cirúrgica. O hemograma prédrenagem revelou: $\mathrm{Htm}: 3,73.10^{5}$; Hto: $27,1 \%$; $\mathrm{Hb}$ : $9,4 \mathrm{~g} \%$; plaquetas: 487.000 ; leucometria: $17.4000 / 2 / 0 / 0 / 1 / 44 / 48 / 5 ; \mathrm{VHS}=83 \mathrm{~mm}$. A drenagem cirúrgica bilateral revelou secreção purulenta. Foi mantido o dreno por 48hs. A curva febril mostrou declínio progressivo, tornando-se afebril no 70 dia após a drenagem (28으 dia de doença). Neste período a tumoração à esquerda tinha involuído muito e à direita havia pequena tumoração palpável. Fez uso da azitromicina por 5 dias após a drenagem. A cultura da secreção obtida a partir da drenagem cirúrgica revelou crescimento de Staphylococcus aureus sensível à oxacilina; exame direto (BAAR) e cultura para micobactéria negativos. O exame histológico revelou material constituído de exsudato leucocitário PMN rico em histiócitos e alguns linfócitos; coloração especial para micobactérias (WADE) negativas para BAAR. A cultura para Nocardia foi negativa. Foi realizado o método de reação de cadeia de polimerase (PCR) para $B$. henselae e $B$. quintana no aspirado de secreção ganglionar, sendo positiva para $B$. quintana.

O hemograma $72 \mathrm{~h}$ após a drenagem revelou: $\mathrm{Htm}: 4,34.10^{5} \mathrm{Hb}: 11,4 \mathrm{~g} \%$; Hto: $32 \%$; plaquetas: 302.000; Leucometria: 10.800; 0/8/0/0/1/30/53/8; VHS $=30 \mathrm{~mm}$. A evolução foi excelente com regressão total da tumoração. O exame oftalmológico realizado após 2 meses foi normal.

\section{DISCUSSÃO}

Este caso ilustra uma evolução típica da Doença da Arranhadura do Gato (DAG), onde a adenomegalia bilateral comprometeu um lactente com história epidemiológica negativa e cujo agente etiológico também foi inusitado, tendo sido isolado a $B$. quintana e não a $B$. henselae, que seria 0 mais provável. $O$ rastreamento diagnóstico excluiu outras possíveis causas de 
adenite, mais comuns nesta faixa etária. $\mathrm{O}$ diagnóstico diferencial entre adenite e envolvimento das glândulas submandibulares se impôs, pois sabemos que o vírus da caxumba, por exemplo, pode comprometer as glândulas submandibulares sem parotidite associada, o que clinicamente é indistinguível de adenite ${ }^{12}$. Por esta razão, a investigação diagnóstica foi ampla, incluindo enterovírus. O rastramento viral foi negativo exceto para o vírus Coxsackie B. Entretanto, este achado foi provavelmente casual, já que não foi possível correlacionar com o quadro clínico. $\mathrm{Na}$ revisão bibliográfica realizada não encontramos descrição de adenomegalia de evolução semelhante relacionada ao vírus.

A investigação para DAG obedeceu ao critério de exclusão, visto que esta possibilidade foi aventada, dada à evolução prolongada e a não resposta evidente ao tratamento empírico com antibioticoterapia. Diante da possibilidade de drenagem cirúrgica, optamos pela realização do método de PCR em material obtido do linfonodo supurado. Não foram realizados testes cutâneos ou sorológicos, em razão da maior sensibilidade do método PCR e também pelo alto custo destes exames no nosso meio.

Em relação à avaliação sorológica, observamos algumas considerações a partir de estudos publicados. Um ensaio clínico prospectivo, controlado com 80 pacientes com DAG, mostrou que os métodos laboratoriais, incluindo $\lg M$ (ELISA) e IFA, têm sensibilidade que variou de 66 a $83 \%$, quando correlacionados à clínica e de 73 a $93 \%$ quando correlacionados ao teste cutâneo, respectivamente. A especificidade variou de $98 \%$ para IFA e $95 \%$ para $\operatorname{lgM}^{19}$. Existe reconhecida reação cruzada entre as diferentes espécies de Bartonella em estudos sorológicos, em razão da presença de determinantes antigênicos comuns ${ }^{111}$. Entretanto, em estudos experimentais em camundongos imunizados com $B$. henselae e $B$. quintana, não observou-se reações cruzadas e sim respostas sorológicas específicas $^{18}$.

O método de PCR é considerado rápido, de grande sensibilidade e especificidade, que elimina a necessidade de realização de outros recursos diagnósticos ${ }^{3}$. PCR e hibridização com sondas de DNA espécie-específicas distingue as espécies $B$. henselae e B. quintana. O PCR apresenta excelente sensibilidade (99-100\%) em pacientes apresentando IgM positivo no líquor ou sangue, podendo também ser detectado em tecidos e urina. Os resultados falsos positivos e falsos negativos são minimizados frente a um protocolo de procedimento rígido.

Os autores têm relatado em estudos, utilizando PCR em tecido de linfonodos de pacientes com DAG, o isolamento de $B$. henselae e não de $B$. quintana ${ }^{18}$. Entretanto, há alguns relatos do envolvimento de $B$. quintana em DAG isoladamente ou em associação com $B$. henselae ${ }^{16}$. Há um consenso que, embora a $B$. henselae seja o agente mais comum, não é o único envolvido na etiologia da DAG ${ }^{1816}$. Portanto, o achado de $B$. quintana pelo método PCR em material purulento a partir de linfonodo, no referido paciente, nos permite com confiabilidade imputá-lo como agente causal.

Não foi possível determinar papel de gatos, cachorros, pulgas ou outros artrópodes na transmissão da doença neste caso. Contato com gato ocorre em média em 95\%, com cachorro em $4 \%$, enquanto nenhuma história de contato animal ocorre em $1 \%{ }^{14}{ }^{15}$. Nesta última situação o diagnóstico depende de um alto nível de suspeição. Não foi observado lesão alvo tipo mordida ou arranhão. Apesar da localização submandibular, não encontramos nenhuma lesão de inoculação em mucosa oral ou ocular.

Clinicamente, vários sinais e sintomas clínicos foram compatíveis com o quadro de DAG. O fato da paciente manter-se bem, apesar da impressionante adenomegalia que apresentava, sem sinais de toxemia em nenhum momento, ainda que mantendo picos febris elevados de até $40^{\circ} \mathrm{C}$ na fase inicial, é muito característico de DAG $^{241420 .}$.

O tamanho da lesão, que ultrapassou cerca de 3 a $4 \mathrm{~cm}$, também é compatível com a doença, assim como o eritema da pele relacionada ao gânglio comprometido. Está descrito que, a hiperemia resolve na medida em que o gânglio diminui de tamanho, e a celulite parece ser um evento raro $^{14}$. A evolução da paciente mostrou um comprometimento de pele com coloração violácea, que sugeria muito celulite. Entretanto, em 48 hs houve melhora, com desaparecimento da lesão cutânea, ainda que mantendo a dimensão do gânglio. Não há como inferir se a evolução favorável teve relação com a antibioticoterapia instituída em vigência de infecção secundária ou se foi a própria evolução da DAG, que habitualmente, é independente da antibioticoterapia. Os gânglios com eritema tendem a regredir mais lentamente e a serem supurativos. Cerca de $15 \%$ dos gânglios supuram ${ }^{14}$. 
A maioria dos linfonodos evolui para um processo variável de liquefação antes da reabsorção. Os gânglios comprometidos freqüentemente coalescem, causando um relativo aumento de volume $^{4}$. A paciente em questão apresentou flutuação bilateral com resposta clínica excelente, a partir da drenagem cirúrgica. Alguns autores não recomendam a drenagem cirúrgica, pois estudos ultrassonográficos têm demonstrado que a supuração com reabsorção do conteúdo nodular liquefeito é o curso natural da doença na quase totalidade dos casos, embora isto seja clinicamente aparente em menos de $10 \%{ }^{14}$. Entretanto, quando o processo supurativo é tão intenso e superficial que a ruptura espontânea é iminente, recomenda-se a aspiração ou drenagem cirúrgica ${ }^{4}$.

Em relação ao quadro laboratorial, foi de nota o aumento importante do VHS. Conforme descrito na literatura, a eosinofilia que a paciente apresentou no $5^{\circ}$ dia de internação poderia estar relacionada ao uso do ceftriaxone, visto que houve uma relação temporal evidente, entre esta alteração laboratorial e a administração do medicamento ${ }^{13}$.

Quanto ao tratamento, há um consenso na literatura que DAG tem um prognóstico excelente com recuperação espontânea em 2 a 6 meses, podendo levar 1 a 2 anos para a adenomegalia regredir totalmente ${ }^{24691114}$. O tratamento, ainda que questionável, tem sido restrito às formas sistêmicas com comprometimento visceral, ósseo, ocular ou do SNC (encefalite) 1101820 . A paciente foi tratada com antibióticos sistêmicos, pois a faixa etária e a epidemiologia eram muito mais compatíveis com adenite bacteriana do que com DAG. Vale ressaltar ainda que o diagnóstico etiológico veio a posteriori, quando o quadro clínico já tinha se definido, tendo apenas um valor histórico e científico, mas não sendo determinante de qualquer conduta.

A paciente usou empiricamente azitromicina após a drenagem durante 5 dias. Está descrito que o uso deste medicamento na fase aguda favorece a diminuição do linfonodo dentro do primeiro mês de tratamento ${ }^{4}$. No caso descrito, o uso foi tardio e provavelmente não interferiu na evolução. O isolamento de Staphylococcus aureus no material drenado provavelmente deveu-se à contaminação secundária, visto que, inicialmente, o paciente foi tratado com antibioticoterapia específica, não sendo portanto, considerado relevante no contexto da doença como agente etiológico primário.

Este caso ilustra a importância do agente Bartonella espécies $B$. henselae e, também, a $B$. quintana na etiologia de quadros de adenomegalia. $O$ autor sugere que a pesquisa de $B$. henselae e $B$. quintana devem fazer parte do rastreamento diagnóstico de adenites, principalmente quando a evolução é subaguda como a do paciente descrito.

\section{REFERÊNCIAS BIBLIOGRÁFICAS}

1. Abbasi S, Chesney PJ. Pulmonary manifestations of CatScratch Disease; a case report and review of the literature. The Pediatric Infectious Disease Journal 14: 547-548, 1995.

2. Anderson BE, Neuman MA. Bartonella spp. as emerging human pathogens. Clinical Microbiology Reviews 10:203219, 1997.

3. Anderson B, Simb K, Regenery R, Robinson L, Schmidt MJ, Goral S, Hager C, Edwards K. Detection of Rochalimaea henselae DNA in specimens from Cat Scratch Disease patients by PCR. Journal of Clinical Microbiology 32:942-948, 1994.

4. Bass JW, Freitas BC, Freitas AD, Sisler CL, Chan DS, Vincent JM, Person DA, Claybaugh JR, Wittler RR, Weisse ME, Regnery RL, Slater LN. Prospective randomized double blind placebo-controlled evaluation of azithromycin for treatment of cat-scratch disease. Pediatric Infectious Disease Journal 17:447-452, 1998.

5. Bass JW, Vicent JM, Person DA. The expanding spectrum of Bartonella infections: I. Bartonellosis and trench fever. Pediatric Infectious Disease Journal 16:2-10, 1997.
6. Bass JW, Vicent JM, Person DA. The expanding spectrum of Bartonella infections: II. Cat-scratch disease. Pediatric Infectious Disease Journal 16:163-179, 1997.

7. Dangman BC, Albanese BA, Kacica MA, Lepow ML, Wallach MT. Cat Scratch Disease in two children presenting with fever of unknown origin: imaging features and association with a new causative agent, Rochalimaea henselae. Pediatrics 95:767-771, 1995.

8. Fumarola D, Giuliani G, Pece S. Cat-Scratch Disease: single or multiple causative microorganisms? The Pediatric Infectious Disease Journal 14: 822, 1995.

9. Giladi M, Avidor B, Kletter Y, Abulafia S, Slater LN, Welch DF, Brenner DJ, Steigerwalt AG, Whitney AM, Ephros M. Cat Scratch Disease: the rare role of Afipia felis. Journal of Clinical Microbiology 36:2499-2502, 1998.

10. Grossman M, Azimi PH. Sudden onset of blurred vision in a thirteen-year-old girl. The Pediatric Infectious Disease Journal 14:1016-1019, 1995.

11. Karpathios T, Golphinos C, Psychou P, Garoufi A, Papadimitriou A, Nicolaidou P. Cat scratch disease in Greece. Archive Disease of Children 78:64-66, 1998. 
12. Krugman S, Ward R, Katz SL. Infectious diseases of children. $6^{\text {th }}$ edition. C.V. Mosby Company Saint Louis, p. 181-193, 1977.

13. Mandell GL, Petri WA Jr. Fármacos antimicrobianos. Penicilinas, cefalosporinas e outros antibióticos blactâmicos. In: Hardman JG, Limbird LE, Molinoff PB, Ruddon RW, Gilman AG (eds) Goodman \& Gilman. As bases farmacológicas da terapêutica. 9a edição, Mc Graw-Hill. Mexico, p. 790-811, 1996.

14. Margileth AM. Cat Scratch Disease. Advances in Pediatric Infectious Diseases 8:1-20, 1993.

15. Noah DL, Bresee JS, Gorensek MJ, Rooney JA, Cresanta JL, Regnery RL, Wong J, Del Toro J, Olson JG, Childs JE. Cluster of five children with acute encephalopathy associated with cat-scratch disease in South Florida. Pediatric Infectious Disease Journal 14:866-869, 1995.

16. Raoult D, Drancourt M, Carta A, Gastaut JA. Bartonella (Rochalimaea) quintana isolation in patient with chronic adenopathy, lymphopenia, and a cat. The Lancet 343:977, 1994.

17. Scully RE, Mark EJ, McNeely WF, Ebeling SH, Phillips LD, Ellender SM. Case Records of the Massachusetts General Hospital. The New England Journal of Medicine 340:1491-1497, 1999.

18. Swischuk LE. Posttraumatic elbow swelling and inflammation. Pediatric Emergency Care 11:317-318, 1995.

19. Szelc-Kelly CM, Goral S, Perez-Perez GI, Perkins BA, Regnery RL, Edwards KM. Serologic responses to Bartonella and Afipia antigens in patients with Cat Scratch Disease. Pediatrics 96:1137-1142, 1995.

20. Tan TQ, Wagner ML, Kaplan SL. Bartonella (Rochalimaea) henselae hepatosplenic infection occuring simultaeously in two siblings. Clinical Infectious Diseases 22:721-722, 1996. 